Methods: The switch plan occurred between April-December 2019. 403 patients (R;189, G;176, D; 38) were eligible for switch. Patients were informed of the plan in advance via a patient information leaflet/hospital clinic visits. Switch refusals, withheld treatments and cancellations were documented and patients were advised to contact the hospital pharmacy/clinical teams if they encountered any concerns, adverse effects or lack of efficacy post switch. The clinician would then advise on subsequent management.

Results: During April-December 2019, 264/403 patients had been successfully switched (R;122, G;109, D;33). 33/403 patients switched back to the originator biologic $(R ; 22, G ; 10 ; D ; 1)$. Of the 22 rheumatology switch back patients; 6 patients reported injection site pain and variably headache, fatigue, disease relapse, gastrointestinal (GI) upset, erythema; $10=$ reported lack of efficacy and variably influenza-type symptoms, relapse in associated psoriasis, difficulty in walking/sleeping, hair loss, excessive perspiration, facial cellulitis, foot drop and Gl upset; 1=blepharitis;1=latex allergy before injection; 3=later declined switch; $1=$ damaged two devices and did not wish to continue biosimilar. Of the 10 gastroenterology switch back patients; 1 =injection site pain; $2=$ lack of efficacy; $1=$ developed needle phobia; $1=$ latex allergy before injection; $1=$ switch detrimental to health; $2=$ unstable disease; $1=$ insomnia; $1=$ pregnancy. The 1 dermatology switch back patient reported injection site pain and bleeding.

$38 / 403$ patients refused the switch and remained on the originator biologic $(R ; 11$, G;27, D;0). 29/403 patients had treatment cancellations and were switched to an alternative biologic $(R ; 17, G ; 9, D ; 3) .32 / 403$ patients stopped treatment $(R ; 13$, G;19, D;0). Treatment was withheld for $7 / 403$ patients (R;4, G;2, D;1).

Conclusion: The UHCW adalimumab biosimilar switch plan succeeded in switching a total of $66 \%$ of patients; thus an annual cost saving of $£ 73,020$. Injection site pain, most likely due to the biosimilar citrate content, and lack of efficacy according to patient perception and subsequent clinical review, were the most predominant causative themes for switch backs. Gastroenterology patients accounted for $71 \%(27 / 38)$ of the total switch refusals. Additional data regarding patient refusals, identifies future opportunities to improve patient counselling and drive further cost savings.

References:

[1] Azevedo V, et al. Biosimilars: considerations for clinical practice. Considerations in Medicine. 2017;1(1):13-8

[2] Lord Carter of Coles. (2016) Operational productivity and performance in English NHS Acute Hospitals: Unwarranted variations [Online]

Acknowledgments: Mark Easter, Chief Pharmacist, Hardeep Bagga, Deputy Chief Pharmacist, UHCW Pharmacy Homecare Team, UHCW Specialist Clinical Teams.

Disclosure of Interests: None declared

DOI: 10.1136/annrheumdis-2020-eular.3880

\section{AB1344-HPR POOLED ANALYSIS OF ASSOCIATION BETWEEN ABATACEPT OR OTHER TARGET DISEASE- MODIFYING ANTI-RHEUMATIC DRUGS (TDMARD) AND TYPE 2 DIABETES MELLITUS (T2DM)-RELATED HEALTHCARE RESOURCE UTILIZATION (HCRU) AND COSTS IN TNFI-NAÏVE RHEUMATOID ARTHRITIS (RA) PATIENTS WITH T2DM}

X. $\operatorname{Han}^{1}$, Q. Xia ${ }^{1}$, Y. Bao ${ }^{1}$, V. Patel ${ }^{1}$, A. Roy ${ }^{2}$, V. Rajagopalan ${ }^{2}$, F. Lobo ${ }^{1}{ }^{1}$ BristolMyers Squibb, Princeton, United States of America; ${ }^{2}$ Mu-Sigma, Bangalore, India

Background: Limited information is available on the impact of target disease-modifying anti-rheumatic drugs (tDMARD) on patients with rheumatoid arthritis (RA) and type 2 diabetes mellitus (T2DM).

Objectives: The objective was to compare T2DM-related healthcare resource utilization ( $\mathrm{HCRU})$ and cost for TNF inhibitors (TNFi)-naive patients pooled from two commercial databases with RA and T2DM receiving abatacept, other nonTNFi, or TNFi.

Methods: A retrospective, observational study was conducted with MarketScan and PharMetrics (January 2008-September 2018). The study population included TNFi-naïve adult patients with RA and T2DM newly initiating abatacept, TNFi (adalimumab, certolizumab pegol, etanercept, golimumab, infliximab) or other non-TNFi (tocilizumab, anakinra, sarilumab, rituximab, tofacitinib). Date of tDMARD initiation was the index date. Patients had $\geq 2$ RA diagnoses separated by $\geq 7$ days, $\geq 1$ T2DM diagnosis, and had $\geq 12$ months of pre-index continuous enrollment. Follow-up ended at the end of patient insurance enrollment, study period or index treatment. T2DM-related HCRU and costs including inpatient stay, outpatient visits, ER visits, and pharmacy use were measured on a per-patient-per-month (PPPM) basis (2018 USD). Patients treated with abatacept were matched to TNFi and non-TNFi cohorts separately by propensity score adjusted with patients baseline comorbidities, HCRU, and costs.

Results: A total of 16,236 patients meeting criteria were identified. Most patients were female $(74.3 \%)$, and the overall average age of 55.4 years (Table 1). After matching, 850 pairs of abatacept vs non-TNFi patients, and 1,096 pairs of abatacept vs TNFi patients were included in the adjusted results. Patients initiating abatacept had $\$ 144$ lower adjusted T2DM-related costs as compared to nonTNFi and $\$ 79$ lower costs than TNFi cohorts (Table 2).

Table 1. Patient Characteristics

\begin{tabular}{lcccc}
\hline & $\begin{array}{c}\text { Abatacept } \\
\mathbf{n = 1 , 1 3 4}\end{array}$ & $\begin{array}{c}\text { Non-TNFi } \\
\mathbf{n = 1 , 3 5 3}\end{array}$ & $\begin{array}{c}\text { TNFi } \\
\mathbf{n = 1 3 , 7 4 9}\end{array}$ & $\begin{array}{c}\text { Total } \\
\mathbf{N}=\mathbf{1 6 , 2 3 6}\end{array}$ \\
\hline Age, mean years (SD) & $58.5(11.3)$ & $57.7(11.2)$ & $54.9(10.6)$ & $55.41(10.7)$ \\
Gender, female, $\mathbf{n}(\%)$ & $936(82.5)$ & $993(73.4)$ & $10,142(73.8)$ & $12,071(74.3)$ \\
CCI, mean (SD) & $2.2(1.4)$ & $2.3(1.4)$ & $1.8(1.1)$ & $1.89(1.14)$ \\
DCSI, $\mathbf{n}(\%)$ & & & & \\
$\quad$ Cardiovascular & $361(31.8)$ & $406(30.0)$ & $2,500(18.2)$ & $3,267(20.1)$ \\
$\quad$ Neuropathy & $294(25.9)$ & $374(27.6)$ & $3,161(23.0)$ & $3,829(23.6)$ \\
Nephropathy & $146(12.9)$ & $193(14.3)$ & $1,151(8.4)$ & $1,490(9.2)$ \\
PVD & $131(11.6)$ & $155(11.5)$ & $874(6.4)$ & $1,160(7.1)$ \\
Retinopathy & $103(9.1)$ & $119(8.8)$ & $922(6.7)$ & $1,144(7.0)$ \\
Cerebrovascular & $74(6.5)$ & $102(7.5)$ & $620(4.5)$ & $796(4.9)$ \\
Metabolic & $9(0.8)$ & $20(1.5)$ & $141(1.0)$ & $170(1.0)$ \\
\hline
\end{tabular}

CCl: Charlson comorbidity index; DCSI: diabetes complications severity index; PVD: peripheral vascular disease.

Table 2. Adjusted T2DM-related HCRU and Costs after Propensity Score Matching

\begin{tabular}{|c|c|c|c|c|c|c|}
\hline & $\begin{array}{c}\text { Abatacept } \\
n=850\end{array}$ & $\begin{array}{c}\text { Non-TNFi } \\
n=850\end{array}$ & $\begin{array}{c}\text { Diff } \\
\text { (ABA- } \\
\text { Non- } \\
\text { TNF) }\end{array}$ & $\begin{array}{c}\text { Abatacept } \\
n=1,096\end{array}$ & $\begin{array}{c}\text { TNFi } \\
\mathrm{n}=1,096\end{array}$ & $\begin{array}{r}\text { Diff } \\
\text { (ABA } \\
\text { TNF) }\end{array}$ \\
\hline \multicolumn{7}{|c|}{ T2DM-related HCRU (per 1000 Patients per Month) } \\
\hline Number of Hospitalizations & 13.9 & 20.4 & $-6.5^{\star}$ & 12.6 & 14.9 & -2.3 \\
\hline $\begin{array}{l}\text { Number of } \\
\text { ER Visits }\end{array}$ & 22.0 & 16.1 & $5.9^{*}$ & 18.4 & 16.3 & $2.0^{*}$ \\
\hline $\begin{array}{l}\text { Number of } \\
\text { Outpatient Visits }\end{array}$ & 311 & 334.8 & $-23.7^{\star}$ & 299.3 & 286.9 & 12 \\
\hline \multicolumn{7}{|c|}{ T2DM-related Costs (PPPM \$) } \\
\hline Inpatient Costs & 507 & 535 & -28 & 413 & 475 & -6 \\
\hline ER Costs & 27 & 17 & $10^{*}$ & 22 & 25 & -3 \\
\hline Outpatient Costs & 190 & 323 & -133 & 186 & 170 & $16^{*}$ \\
\hline Pharmacy Costs & 107 & 100 & $7^{\star}$ & 97 & 128 & -31 \\
\hline Total Costs & 831 & 975 & -144 & 719 & 798 & $-79^{*}$ \\
\hline
\end{tabular}

${ }^{*} \mathrm{P}<0.05$

Conclusion: TNFi-naive RA patients with T2DM newly initiating abatacept had lower adjusted rates of T2DM-related hospitalizations compared to patients who initiated a non-TNFi or a TNFi. Total costs were lower among patients initiating abatacept vs. patients who initiated a non-TNFi or a TNFi. Findings suggest that initial abatacept among TNFi-naïve patients may be able to reduce healthcare utilization arising from T2DM complications and reduce T2DM-related costs in RA patients.

Disclosure of Interests: Xue Han Employee of: BMS, Qian Xia Shareholde of: I own shares of Bristol-Myers Squibb Company, Employee of: I am a paid employee of Bristol-Myers Squibb Company, Ying Bao Shareholder of: Bristol-Myers Squibb, Employee of: Bristol-Myers Squibb, Vardhaman PATEL Employee of: Bristol Myers Squibb, Amrina Roy Employee of: Mu-Sigma, Varshini Rajagopalan Employee of: Mu-Sigma, Francis Lobo Shareholder of: Bristol-Myers Squibb (US), Employee of: Bristol-Myers Squibb (US) DOI: 10.1136/annrheumdis-2020-eular.3912

\section{AB1345-HPR THE MULTIDISCIPLINARY FOOT CLINIC: A SERVICE EVALUATION PROJECT}

G. Jevons ${ }^{1}$, H. Edginton ${ }^{1}$, G. Mccall ${ }^{1}$, A. Pillai ${ }^{1}$, S. Haque ${ }^{1} .{ }^{1}$ Manchester University NHS Foundation Trust, Southmoor Road, United Kingdom

Background: Patients with rheumatological foot disease are an overlooked population, and it was noted locally that these patients received a fragmented service; attending multiple appointments for the management of one clinical issue. This led to delays in treatment; significant inter-departmental correspondence and variations in the peri-operative management of disease modifying anti-rheumatic drug (DMARD) and biologic therapies. To remedy this a foot multidisciplinary (MDT) clinic was established, including input from rheumatology, orthopaedic surgery, specialist rheumatology podiatry and physiotherapy. The outcomes from the foot MDT clinic have been analysed in this service evaluation project.

Objectives: To evaluate the outcomes of the multidisciplinary foot MDT clinic with particular reference to concordance to the British Rheumatology Society (BSR) guidelines on peri-operative medicine guidelines

Methods: Data was collected retrospectively across all clinics from January 2017 to February 2019. Clinic letters were obtained, and data was collected using a standardised data collection sheet. Data was collected on patient demographics, rheumatological diagnoses, treatment outcomes from the foot MDT 